\title{
Factors Associated with In-hospital Death in Patients with Acute Mesenteric Artery Ischemia
}

\author{
Előd Etele Élthes ${ }^{1}$, Alexandra Lavinia Cozlea ${ }^{2}$, Árpád Török ${ }^{1}$ \\ ${ }^{1}$ 2nd Department of General Surgery, County Clinical Emergency Hospital, Tîrgu Mureș, Romania \\ ${ }^{2}$ Department of Gynecology, County Clinical Emergency Hospital, Tîrgu Mureș, Romania
}

\section{ABSTRACT}

Objective: The aim of the study was to assess the factors associated with increased mortality in patients with acute mesenteric ischemia, emphasizing the importance of an early diagnosis and a prompt surgical intervention in order to avoid lesion progression. Materials and method: A retrospective analytical study was conducted on a study population of 50 male and female patients with acute ischemia of the mesenteric arteries, aged between 36-92 years. Demographic and pathological history characteristics were assessed, together with presented symptoms, laboratory and CT findings, as well as surgical outcome and time-related aspects between presentation in the emergency department and time of surgery, as well as the hospitalization period until discharge or death. Results: Muscular defense $(\mathrm{OR}=23.05)$ and shock $(\mathrm{OR}=13.24)$ as symptoms were strongly associated with a poor prognosis, while elevated values of lactate dehydrogenase $(p=0.0440)$ and creatine kinase $(p=0.0025)$ were associated with higher death rates. The time elapsed during investigations in the emergency room was significantly higher in patients who deceased $(\mathrm{p}=0.0023)$, similarly to the total time from the onset of symptoms to the beginning of surgery $(\mathrm{p}=0.0032)$. Surgical outcomes showed that patients with segmental ischemia of the small bowel had significantly higher chances of survival $(p<0.0001)$. Conclusion: Increased mortality rates in patients presenting in the emergency department for acute mesenteric ischemia were observed in patients with occlusion of the superior mesenteric artery, with higher levels of CK and LDH, as well as with longer periods of stay in the emergency department for diagnostic procedures until the commencement of the surgical intervention. Therefore, proper investigations in a timely manner followed by a specific and prompt surgical intervention may avoid unfavorable evolution of patients towards death.

Keywords: bowel, ischemia, mortality, evolution, surgery

\section{ARTICLE HISTORY}

Received: August 18, 2018

Accepted: September 17, 2018

\section{CORRESPONDENCE}

\section{Alexandra Lavinia Cozlea}

Str. Gheorghe Marinescu nr. 50

540136 Tîrgu Mureș, Romania

Tel: +40 265212111

E-mail: alexandra.cozlea@gmail.com

\section{INTRODUCTION}

Acute mesenteric ischemia (AMI) is a life-threatening complex medical condition, characterized by a sudden interruption of blood supply to a segment of small intestine, being considered a major vascular emergency. If untreated, it leads to ischemia and death. The incidence of this critical condition is around $0.1-0.2 \%$ among all acute presentations in the emergency room. ${ }^{1}$
Despite the developments achieved in the diagnostic and therapeutic measures applied in AMI, mortality rates continue to be high, approximately $50-80 \%$. AMI is often not recognized or misdiagnosed, due to lack of specific symptoms and specific laboratory markers. Acute obstruction of the superior mesenteric artery (SMA) leads to irreversible intestinal damage within a few hours, a prompt diagnosis and early surgical treatment being crucial to prevent the 
progression of intestinal necrosis. Without specific treatment, this condition evolves towards peritonitis, sepsis, and eventually multiple organ failure.

The aim of the study was to assess the factors associated with increased mortality in patients with acute mesenteric ischemia, emphasizing the importance of an early diagnosis and a prompt surgical intervention in order to avoid lesion progression.

\section{MATERIAL AND METHOD}

A retrospective analytic observational study was performed in the 2nd Department of General Surgery of the County Clinical Emergency Hospital Tîrgu Mureș, Romania, including 50 male and female patients diagnosed with AMI of different etiologies, admitted between 2014 and 2016. Patients were selected and divided into two groups based on the evolution of the pathology, as follows: Group 1 included patients who deceased due to AMI ( $\mathrm{n}=37$ ), while patients who survived AMI were included in Group $2(n=13)$.

Data gathered from the medical records included the following: (1) demographic features and pathological background of the study subjects, including gender, age, cardiovascular risk factors, and associated diseases (peripheral artery disease, cerebrovascular illness, diabetes mellitus, coagulation disorders); (2) clinical signs and symptoms at the time of presentation; (3) paraclinical assessment: laboratory exams (white blood cell count, lactate dehydrogenase $[\mathrm{LDH}]$, creatine kinase [CK], aspartate aminotransferase [AST], alanine aminotransferase [ALT], glucose, urea, creatinine, potassium, sodium, Quick time, INR) and computed tomography (CT) results; (4) AMI aspects: type, extension, and locations; (5) surgical treatment and outcomes. Furthermore, the time passed from the moment of presentation at the emergency room and commencement of surgery was analyzed.

Collected data was processed using Microsoft Excel, and the statistical analysis was performed using GraphPad InStat software (GraphPad Software, Inc., San Diego, USA). Quantitative variables were expressed by mean and median, qualitative and categorical variables being presented as integer and percentage values. Inferential statistical analysis was performed using Fisher's exact test, categorical data was evaluated using logistic regression, while quantitative variables were analyzed using the Mann-Whitney or Student's t-test when appropriate. Correlation analysis was conducted using the Spearman correlation coefficient. The level of statistical significance was set at a p value of 0.05 .

\section{RESULTS}

\section{PATIENT DEMOGRAPHICS, MEDICAL HISTORY, AND CLINICAL PRESENTATION}

The statistical analysis showed that the age group with the highest risk of death included patients over 80 years, with a calculated odds ratio of 1.36 , but with no statistical significance. Related to gender distribution, it was ob-

TABLE 1. Patient medical history and associated disease

\begin{tabular}{|c|c|c|c|c|}
\hline & $\begin{array}{c}\text { Group 1 } \\
\text { (deceased) } \\
\mathbf{n}=37(\%)\end{array}$ & $\begin{array}{c}\text { Group 2 } \\
\text { (survivors) } \\
n=13(\%)\end{array}$ & $\begin{array}{l}\text { Odds Ratio } \\
\quad \text { (OR) }\end{array}$ & $p$ value \\
\hline \multicolumn{5}{|l|}{ Age (years) } \\
\hline$<60$ & $5(13.51)$ & $2(15.39)$ & 0.86 & 1.0000 \\
\hline $60-80$ & $15(40.54)$ & $6(46.15)$ & 0.79 & 0.7539 \\
\hline$>80$ & $17(45.95)$ & $5(38.46)$ & 1.36 & 0.7510 \\
\hline \multicolumn{5}{|l|}{ Gender } \\
\hline Male & $24(64.86)$ & $7(53.85)$ & 1.58 & 0.5213 \\
\hline Female & $13(35.14)$ & $6(46.15)$ & 0.63 & 0.5213 \\
\hline \multicolumn{5}{|l|}{ Cardiovascular pathologies } \\
\hline Atrial fibrilation & $17(45.95)$ & $7(53.85)$ & 0.73 & 0.7505 \\
\hline Other cardiovascular diseases & $36(97.3)$ & $13(100)$ & 0.90 & 1.0000 \\
\hline Coagulopathies & $3(8.11)$ & $1(7.69)$ & 1.05 & 1.0000 \\
\hline Diabetes & $8(21.62)$ & $3(23.07)$ & 0.91 & 1.0000 \\
\hline Peripherical vascular disease & $8(21.62)$ & $1(7.69)$ & 3.31 & 0.4141 \\
\hline Cerebrovascular accident & $10(27.03)$ & $1(7.69)$ & 4.44 & 0.2476 \\
\hline
\end{tabular}


served that male patients presented higher odds of mortality caused by AMI $(\mathrm{OR}=1.58)$, despite the low statistical significance of the results.

Table 1 presents the statistical analysis of the pathological history in the studied patients, which revealed that cardiovascular diseases had no impact on the risk of death due to AMI $(\mathrm{OR}=0.73, \mathrm{OR}=0.90)$. Also, calculated chances for a critical evolution of patients diagnosed with coagulopathies and subsequent AMI showed no statistical relevance $(\mathrm{OR}=1.05)$. The presence of diabetes mellitus in the patients' pathological history showed no influence on the risk of death due to AMI (OR = 0.91). Associated peripherical vascular disease presented increased odds for an unfavorable prognosis of the intestinal ischemia $(\mathrm{OR}=3.31)$. A history of cerebrovascular accidents increased the risk of a negative prognosis in patients with AMI $(\mathrm{OR}=4.44)$, but with no statistical significance.

The patients presented varied AMI symptomatology, as shown in Table 2.

Abdominal pain was the most frequent symptom, but without an additional risk for death $(\mathrm{OR}=0.90)$, a similar situation being observed for abdominal meteorism (OR = 0.65). Nausea and vomiting were also found in high percentages in both study groups. In case of lack of bowel motility, skin mottling and fever at presentation presented high odds for an unfavorable prognosis, and subjects with muscular defense at presentation had significantly higher mortality ( $O R=23.05, p=0.0019)$. Also, patients found in shock were more likely to have an unfavorable evolution

TABLE 2. Symptomatology, laboratory and CT findings in patients with AMI

\begin{tabular}{|c|c|c|c|c|}
\hline & $\begin{array}{c}\text { Group 1 } \\
\text { (deceased) } \\
n=37(\%)\end{array}$ & $\begin{array}{c}\text { Group 2 } \\
\text { (survivors) } \\
n=13(\%)\end{array}$ & $\begin{array}{l}\text { Odds Ratio } \\
\quad \text { (OR) }\end{array}$ & $p$ value \\
\hline \multicolumn{5}{|l|}{ Symptomatology } \\
\hline Abdominal pain & $36(97.3)$ & $13(100)$ & 0.90 & 1.0000 \\
\hline Abdominal meteorism & $16(43.24)$ & $7(53.85)$ & 0.65 & 0.5369 \\
\hline Nausea & $16(43.24)$ & $11(84.61)$ & 0.14 & 0.0119 \\
\hline Vomiting & $15(40.54)$ & $10(76.92)$ & 0.20 & 0.0500 \\
\hline No bowel motility & $26(70.27)$ & $6(46.15)$ & 2.76 & 0.1797 \\
\hline Muscular defense & $17(45.95)$ & $0(0)$ & 23.05 & 0.0019 \\
\hline Skin mottling & $5(13.51)$ & $0(0)$ & 4.57 & 0.3087 \\
\hline Fever & $5(13.51)$ & $0(0)$ & 4.57 & 0.3087 \\
\hline Shock & $12(32.43)$ & $0(0)$ & 13.24 & 0.0222 \\
\hline \multicolumn{5}{|l|}{ Laboratory findings } \\
\hline WBC & $16.69 * 1000 / \mu \mathrm{L}$ & $18.55^{*} 1000 / \mu \mathrm{L}$ & & 0.3679 \\
\hline LDH & $392.92 \mathrm{U} / \mathrm{L}$ & $249.13 \mathrm{U} / \mathrm{L}$ & & 0.0440 \\
\hline CK & $657.07 \mathrm{U} / \mathrm{L}$ & 199 U/L & & 0.0025 \\
\hline AST & $50.44 \mathrm{U} / \mathrm{L}$ & $47.69 \mathrm{U} / \mathrm{L}$ & & 0.9647 \\
\hline ALT & $36.09 \mathrm{U} / \mathrm{L}$ & $33.54 \mathrm{U} / \mathrm{L}$ & & 0.8769 \\
\hline Glucose & $207.62 \mathrm{mg} / \mathrm{dL}$ & $172.92 \mathrm{mg} / \mathrm{dL}$ & & 0.6743 \\
\hline Urea & $98.78 \mathrm{mg} / \mathrm{dL}$ & $72.16 \mathrm{mg} / \mathrm{dL}$ & & 0.0491 \\
\hline Creatinine & $2.19 \mathrm{mg} / \mathrm{dL}$ & $1.64 \mathrm{mg} / \mathrm{dL}$ & & 0.1703 \\
\hline $\mathrm{K}+$ & $4.35 \mathrm{mmol} / \mathrm{L}$ & $4.21 \mathrm{mmol} / \mathrm{L}$ & & 0.5000 \\
\hline $\mathrm{Na}$ & $139.45 \mathrm{mmol} / \mathrm{L}$ & $138.01 \mathrm{mmol} / \mathrm{L}$ & & 0.4860 \\
\hline TQ & $19.09 \mathrm{~s}$ & $23.04 \mathrm{~s}$ & & 0.3472 \\
\hline INR & 2.03 & 2.05 & & 1.0000 \\
\hline \multicolumn{5}{|l|}{ CT assessment } \\
\hline Obstruction of SMA & $15(40.54)$ & $3(23.08)$ & 2.27 & 0.3281 \\
\hline Obstruction of SMV & $1(2.70)$ & $1(7.69)$ & 0.33 & 0.4563 \\
\hline Hydroaeric level & $28(75.68)$ & $10(76.92)$ & 0.93 & 1.0000 \\
\hline Enlarged intestinal loops & $12(32.43)$ & $7(53.84)$ & 0.41 & 0.1991 \\
\hline Intraabdominal fluid & $16(43.24)$ & $3(23.08)$ & 2.54 & 0.3203 \\
\hline Pneumoperitoneum & $4(10.81)$ & $0(0)$ & 3.63 & 0.5614 \\
\hline
\end{tabular}


TABLE 3. Elapsed times from presentation to surgery

\begin{tabular}{lccc}
\hline & $\begin{array}{c}\text { Group 1 } \\
\text { (deceased) } \\
\mathbf{n = 3 7}\end{array}$ & $\begin{array}{c}\text { Group 2 } \\
\text { (survivors) } \\
\mathbf{n = 1 3}\end{array}$ & p value \\
\hline $\begin{array}{l}\text { (1) Diagnosis time: emergency room presentation } \\
- \text { admission to Surgery Clinic (mean, hours) }\end{array}$ & 7.33 & 4.16 & 0.0023 \\
$\begin{array}{l}\text { (2) Surgical time: admission to surgery clinic } \\
\text { debut of surgery (mean, hours) }\end{array}$ & 1.77 & 1.42 & 0.5000 \\
$\begin{array}{l}\text { Total elapsed time from emergency room presen- } \\
\text { tation to the beginning of surgery (mean, hours) }\end{array}$ & 9.10 & 5.57 & 0.0032 \\
\hline
\end{tabular}

towards death $(\mathrm{OR}=13.24)$, the results being statistically significant $(\mathrm{p}=0.0222)$.

\section{LABORATORY AND IMAGING PARAMETERS}

Most of the laboratory parameters showed no differences between patients who deceased and survived (Table 2). Differences were observed for $\mathrm{LDH}$, the mean of values being significantly higher in Group 1 compared to Group 2 $(\mathrm{p}=0.0440)$. Also, CK showed significantly higher values for patients who deceased ( $\mathrm{p}=0.0025)$.

CT examination showed high chances for a negative prognosis $(\mathrm{OR}=2.27)$ in patients with obstruction of the SMA, presence of intraabdominal fluid $(\mathrm{OR}=2.54)$, and pneumoperitoneum $(\mathrm{OR}=3.63)$, but without statistical relevance. Obstruction of the superior mesenteric vein, hydroaeric levels, and enlarged intestinal loops did not prove to influence the patients' prognosis (Table 2).

\section{ELAPSED TIMES FROM PRESENTATION TO SURGERY}

The most important section of this study was assessing the total elapsed time from the patients' presentation to the emergency department to the beginning of surgery, as presented in Table 3. The total elapsed time was divided into two different periods: (1) time from emergency presentation to admission into the surgery department, noted as the diagnosis time; (2) time from surgery department admission to the beginning of surgical intervention, noted as the surgical time.

The statistical analysis of the time passed from the emergency room presentation to the surgery department consult and admission showed an average of 7.33 hours for Group 1 (deceased patients) and an average of 4.16 hours for Group 2 (survivors), the difference being statistically highly significant $(\mathrm{p}=0.0023)$. The average surgical time was 1.74 hours for Group 1 and 1.42 hours for Group 2 ( $\mathrm{p}=$ 0.5000). When analyzing the total elapsed time, an average of 9.10 hours was calculated for Group 1 and 5.57 hours for Group $2(\mathrm{p}=0.0022)$ (Table 3). Figure 1 presents the time delay from the emergency room presentation until the commencement of the surgical intervention in relation to mortality.

For both patients who had deceased and survived, the time delay until the beginning of surgery and the number of days until discharge or death were evaluated. The

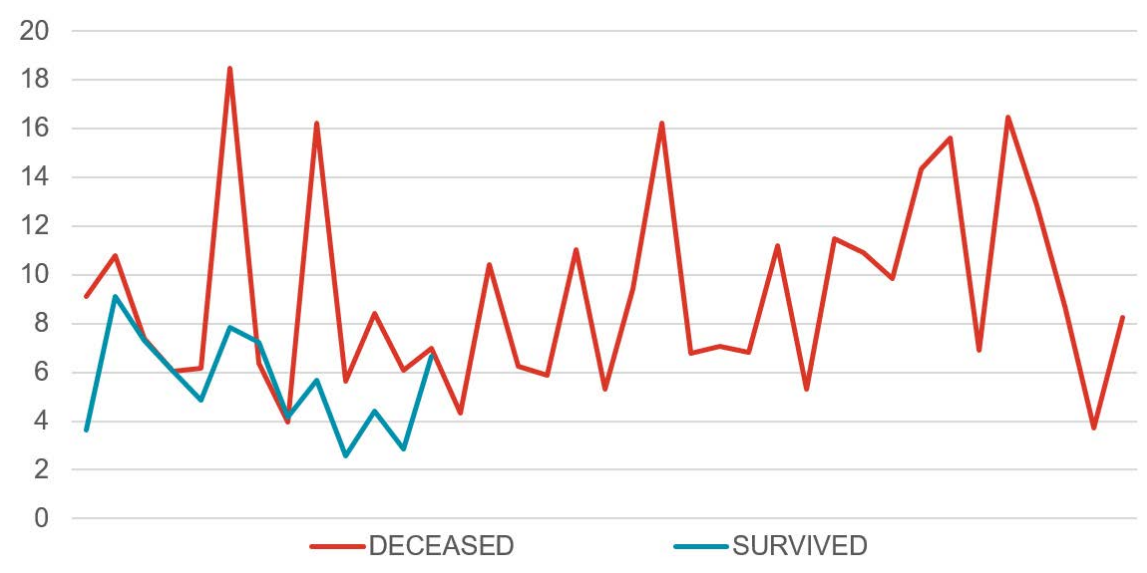

FIGURE 1. Time passed from emergency presentation (hours) to surgical intervention in relation with mortality 
TABLE 4. Delayed time of surgery in relation to days until discharge/death

\begin{tabular}{lcccc}
\hline & $\begin{array}{c}\text { Total elapsed time } \\
\text { from presentation } \\
\text { to the beginning of } \\
\text { surgery (hours) }\end{array}$ & $\begin{array}{c}\text { Time until discharge/ } \\
\text { death (days) }\end{array}$ & r value & p value \\
\hline Group 1 (deceased) & 9.10 & 4.45 & 0.2775 & 0.0963 \\
Group 2 (survivors) & 5.57 & 13.31 & 0.1853 & 0.5444 \\
\hline
\end{tabular}

average postoperative survival period was 4.45 days for Group 1, and the correlation coefficient calculated between the survival period and the surgical time was $\mathrm{r}=$ $0.2775, p=0.096$, without being statistically significant. Patients from Group 2 presented an average hospital stay of 13.31 days, while the calculated correlation coefficient $(r=0.1853)$ described a weak positive association with the delayed moment of surgery, without statistical relevance (Table 4).

\section{SURGICAL, INTRAOPERATIVE, AND POSTOPERATIVE ASPECTS}

Aspects regarding the surgical intervention and intraoperative findings were also evaluated in order to determine the parameters that influence the patients' prognosis, as presented in Table 4.

Intraoperatively, the type of mesenteric ischemia was confirmed. Patients in Group 1 presented an arterial etiology in much higher percentages, this type of ischemia implying a higher risk for a bad prognosis (OR $=3.40$, $\mathrm{p}=0.172$ ). Regarding the extension of ischemia, it was observed that the majority of patients from Group 2 presented a segmental ischemia of the small bowel, aspect that could represent a positive prognostic factor in patients with AMI $(\mathrm{OR}=0.05)$, which was extremely significant from a statistical point of view ( $p$ <.0001). Extended ischemia of the small bowel was found predominantly in Group 1, being significantly associated with higher chances of death $(\mathrm{OR}=32.2, \mathrm{p}<0.0001)$. Also, large bowel involvement fol-

TABLE 5. Surgical, intraoperative, and postoperative aspects

\begin{tabular}{|c|c|c|c|c|}
\hline & $\begin{array}{c}\text { Group 1 } \\
\text { (deceased) } \\
\mathbf{n}=37(\%)\end{array}$ & $\begin{array}{c}\text { Group 2 } \\
\text { (survivors) } \\
\mathbf{n}=13(\%)\end{array}$ & $\begin{array}{l}\text { Odds Ratio } \\
\quad \text { (OR) }\end{array}$ & $\mathrm{p}$ value \\
\hline \multicolumn{5}{|l|}{ Type of ischemia } \\
\hline Arterial & $34(91.89)$ & $10(76.92)$ & 3.40 & 0.1729 \\
\hline Venous & $2(5.40)$ & $1(7.69)$ & 0.68 & 1.0000 \\
\hline Non-oclusive & $1(2.7)$ & $1(7.69)$ & 0.33 & 0.4563 \\
\hline Mechanical & $1(2.7)$ & $1(7.69)$ & 0.33 & 0.4563 \\
\hline \multicolumn{5}{|l|}{ Extension and location of ischemia } \\
\hline Segmental ischemia of small bowel & $5(13.51)$ & $10(76.92)$ & 0.05 & $<0.0001$ \\
\hline Extended ischemia of small bowel & $32(86.49)$ & $2(15.38)$ & 32.2 & $<0.0001$ \\
\hline Large bowel involvement & $16(43.24)$ & $2(15.38)$ & 4.19 & 0.0985 \\
\hline \multicolumn{5}{|l|}{ Type of surgery } \\
\hline Exploratory laparotomy & $26(70.27)$ & $0(0)$ & - & $<0.0001$ \\
\hline Segmental resection & $11(29.73)$ & $11(84.62)$ & - & 0.0009 \\
\hline By-pass surgery & o (o) & $1(7.69)$ & - & 0.2600 \\
\hline Thrombectomy & $1(2.7)$ & $0(0)$ & - & 1.0000 \\
\hline Resection of adhesions & $0(0)$ & $1(7.69)$ & - & 0.2600 \\
\hline \multicolumn{5}{|l|}{ Consequences of AMI } \\
\hline Perforation & $8(21.62)$ & $1(7.69)$ & 3.31 & 0.4141 \\
\hline Peritonitis & $8(21.62)$ & $1(7.69)$ & 3.31 & 0.4141 \\
\hline Sepsis & $4(10.81)$ & $1(7.69)$ & 1.45 & 1.0000 \\
\hline Hemoperitoneum & $0(0)$ & o (o) & - & - \\
\hline
\end{tabular}


lowing AMI was found in higher percentages in Group 1 $(\mathrm{OR}=4.19, \mathrm{p}=0.098)$. Furthermore, there was a significantly higher number of exploratory laparotomies performed for Group 1 (deceased) in comparison to Group 2 (survivors) ( $\mathrm{p}<0.0001$ ), while segmental resections were preponderantly performed in Group 2 ( $\mathrm{p}=0.0009$ ). By-pass, thrombectomy, and resection of adhesions as surgical treatment options showed no significant differences between the two studied groups. In case of surgical complications of AMI, including perforation $(\mathrm{OR}=3.31)$, peritonitis $(\mathrm{OR}=3.31)$, and sepsis $(\mathrm{OR}=1.45)$, there were no statistically significant differences between the two groups, despite the resulted odds ratios (Table 5).

\section{DISCUSSIONS}

When evaluating the demographic characteristics of the study groups, age and gender did not prove to be involved in the outcome of patients, even if a higher incidence of intestinal ischemia was observed with aging, similarly to other authors' results. ${ }^{2}$ The patients' medical history was also analyzed, including existing cardiovascular or coagulation disorders, diabetes mellitus, peripheral vascular pathologies, and previous cerebrovascular accidents; however, these were not significantly associated with the evolution of patients towards death or survival, despite the high odds ratios calculated in some of the previously mentioned comorbidities. Previously published studies have also reported similar results. ${ }^{3}$ Regarding the symptomatology of AMI, several other authors have reported that the most typical symptom is abdominal pain, initially visceral, diffused, non-localized, possibly moderate to severe, without antalgic posture, followed by nausea and vomiting. ${ }^{4}$ In the present study groups, we observed that symptoms associated with a negative prognosis included the presence of muscular defense and shock, which are considered markers of a severely complicated AMI. Other authors reported similar results. ${ }^{5}$ Among the laboratory tests performed in the emergency department, the only ones involved in the prognosis of patients with acute intestinal ischemia were $\mathrm{CK}$ and $\mathrm{LDH}$, these serological markers being significantly more elevated in patients who had deceased, compared to survivors. However, to lean on laboratory findings as possible prognostic markers is not reliable. Other authors have reported similar results. ${ }^{6} \mathrm{Ac}-$ cording to the findings of the present study, none of the signs evaluated via computed tomography were significantly involved in the outcome of AMI patients, despite the high odds ratios calculated for the obstruction of the superior mesenteric artery, the presence of intraabdomi- nal fluid or pneumoperitoneum, but other authors reported more specific results regarding the CT assessment in patients with AMI. ${ }^{7-10}$

Time aspects were an essential part that has been analyzed throughout the present study. In order to emphasize the importance of a prompt surgical intervention in patients with AMI, as mentioned before, we structured the time interval into two parts. The first time interval, in which proper diagnostic investigations were performed, has been proved to be almost two times longer in patients who had deceased, in comparison to patients who survived. We found a statistically important correlation with the total elapsed time, which included the total time from presentation in the emergency department until the actual surgical procedure. Other authors also reported similar results regarding the importance of time and promptitude in diagnosing AMI. ${ }^{11-13}$ The second time interval was the period from admission in the surgery department to the beginning of the surgical intervention, the "surgical time", which was slightly longer in the deceased compared to survivors, these results being in accordance with other reports in the literature. ${ }^{11-13}$ Total time from the onset of symptoms and emergency presentation to the debut of surgical intervention was extremely longer for patients who had died. The period required for extended investigations in order to achieve an accurate diagnosis of AMI had an immense influence on mortality rates, despite the timely surgical intervention after admission. Therefore, patients who were stationed in the emergency department for longer periods of time, experienced a fast lesion progression specific to acute intestinal ischemia, which led surgeons to face situations impossible to manage, leading to the death of patients. The same results were described by other reports in the current literature. ${ }^{11-13}$

Regarding the intraoperative and postoperative surgical aspects, the type of ischemia did not represent any significant involvement in the evolution of patients with AMI, the extension and location of intestinal ischemia being the most important aspect. We observed that segmental ischemia of the small bowel was associated with survival, while extended ischemia ended in most cases with death, which can be attested by several literature reports..$^{14}$ In the present study, the involvement of different segments of the large bowel by AMI did not present any significant impact on patient outcomes; however, other studies do confirm that in case of existing lesions of the caecum, ascendant, transverse, or descendent colon, patient prognosis is reserved..$^{14}$ The surgical procedure was initiated in all cases, but in the majority of patients from Group 1, an exploratory laparotomy revealed extended lesions of the intestines 
and the impossibility of performing a repairing procedure, while for patients belonging to Group 2, segmental resections, by-pass surgery, and adhesiolysis were able to restore intestinal function, followed by survival. Related to the surgical procedures, published studies reported close results. ${ }^{15,16}$ Analyzing the consequences of AMI - such as perforation, peritonitis, or sepsis - showed no statistical impact on the evolution of patients included in our study due to the few existing cases, other authors reporting important associations between AMI complications and negative evolution of patients. ${ }^{17}$ As a summary, it can be said that early diagnosis is indispensable for an effective treatment, being the only way to keep mortality rates low. ${ }^{18-20}$

\section{CONCLUSION}

According to this study, the main cause of intestinal ischemia was the occlusion of the superior mesenteric artery, while patients' medical history showed no significant risks regarding the development of the mesenteric ischemic process. More frequently, a non-specific onset of symptoms was observed, but laboratory exams (LDH and CK) showed higher values in patients who subsequently died. Elapsed time from onset of symptoms and emergency room presentation to the beginning of surgery proved to be significantly longer in patients with a somber prognosis. Avoiding misdiagnosis but also prolonged investigations, which according to this study are directly associated with an increase in mortality, could offer patients with acute mesenteric ischemia a better chance of survival. Therefore, we can affirm that proper investigations in a timely manner, followed by a specific and prompt surgical intervention, may avoid the unfavorable evolution of patients towards death, simultaneously expanding the survival rate in patients with acute mesenteric ischemia.

\section{CONFLICT OF INTEREST}

Nothing to declare.

\section{REFERENCES}

1. Bala M, Kashuk J, Moore EE, et al. Acute mesenteric ischemia: guidelines of the World Society of Emergency Surgery. World J Emerg Surg. 2017;2:38. doi: 10.1186/s13017-017-0150-5.

2. Aouini F, Bouhaffa A, Baazaoui J, et al. Acute mesenteric ischemia: study of predictive factors of mortality. Tunis Med. 2012;90:533-536.

3. Yildirim D, Hut A, Tatar C, Dönmez T, Akıncı M, Toptaş M. Prognostic factors in patients with acute mesenteric ischemia. Turk J Surg. 2017;33:104-109. doi: 10.5152/UCD.2016.3534.
4. Mastoraki A, Mastoraki S, Tziava E, et al. Mesenteric ischemia: Pathogenesis and challenging diagnostic and therapeutic modalities. World J Gastrointest Pathophysiol. 2016;7:125130. doi: 10.4291/wjgp.v7.i1.125.

5. Acosta S. Surgical management of peritonitis secondary to acute superior mesenteric artery occlusion. World J Gatroenterol. 2014;20:9936-9941. doi: 10.3748/wjg.v20. i29.9936.

6. Tilsed JV, Casamassima A, Kurihara H, et al. ESTES guidelines: acute mesenteric ischemia. Eur J Trauma Emerg Surg. 2016;42:253-270. doi: 10.1007/s00068-016-0634-0.

7. Moschetta M, Telegrafo M, Rella L, et al. Multi-detector CT features of acute intestinal ischemia and their prognostic correlations. World J Radiol. 2014;6:130-138. doi: 10.4329/wjr. v6.i5.130.

8. Reginelli A, Iacobellis F, Berritto D, et al. Mesenteric ischemia: the importance of differential diagnosis for the surgeon. BMC Surg. 2013;13(Sl2):S51. doi: 10.1186/1471-2482-13-S2-S51.

9. Dhatt HS, Behr SC, Miracle A, Wang ZJ, Yeh BM. Radiological Evaluation of Bowel Ischemia. Radiol Clin North AM. 2015;53:1241-1254. doi: 10.1016/j.rcl.2015.06.009.

10. Menke J. Diagnostic accuracy of multidetector CT in acute mesenteric ischemia: systematic review and meta-analysis. Radiology. 2010;256:93-101. doi:10.1148/radiol.10091938.

11. Aliosmanoglu I, Gul M, Kapan M, et al. Risk factors effecting mortality in acute mesenteric ischemia and mortality rates: a single center experience. Int Surg. 2013;98:76-81. doi: 10.9738/CC112.1.

12. Duran M, Pohl E, Grabitz K, Schelzig H, Sagban TA, Simon F. The importance of open emergency surgery in the treatment of acute mesenteric ischemia. World J Emerg Surg. 2015;10:45. doi: 10.1186/s13017-015-0041-6.

13. Klar E, Rahmanian PB, Bücker A, Hauenstein K, Jauch KW, Luther B. Acute mesenteric ischemia: a vascular emergency. Dtsch Arztebl Int. 2012;109:249-256. doi: 10.3238/ arztebl.2012.0249.

14. Akyildiz HY, Sözüer E, Uzer H, Baykan M, Oz B. The length of necrosis and renal insufficiency predict the outcome of acute mesenteric ischemia. Asian J Surg. 2015;38:28-32. doi: 10.1016/j.asjsur.2014.06.001.

15. Oldenburg WA, Lau LL, Rodenberg TJ, Edmonds HJ, Burger CD. Acute mesenteric ischemia. Arch Intern Med. 2004;164:10541062. doi: 10.1001/archinte.164.10.1054.

16. Kougias P, Lau D, El Sayed HF, et al. Determinants of mortality and treatment outcome following surgical interventions for acute mesenteric ischemia. J Vasc Surg. 2007;46:467-474. doi: 10.1016/j.jvs.2007.04.045.

17. Huang $\mathrm{HH}$, Chang YC, Yen $\mathrm{DH}$, et al. Clinical factors and outcomes in patients with acute mesenteric ischemia in the emergency department. J Chin Med Assoc. 2005;68:299-306. doi: 10.1016/S1726-4901(09)70165-0.

18. Rosero O, Harsányi L, Szíjártó A. Acute mesenteric ischemia: Do biomarkers contribute to diagnosis? Orv Hetil. 2014;155:16151623. doi: 10.1556/OH.2014.30013.

19. Simunic M, Fabijanic D, Perkovic N, et al. Acute mesenteric ischemia due to superior mesenteric artery embolism in a patient with permanent atrial fibrillation. Signa Vitae. 2010;5:40-43. doi: 10.22514/SV51.042010.6.

20. Wu MY, Lee LC, Chen YL, et al. Ischemic bowel disease due to superior mesenteric artery occlusion: A case report. Reports. 2018;1:10. doi:10.3390/reports1010010. 